\title{
PRODUTIVIDADE E QUALIDADE DE UVAS DA CV. ISABEL (Vitis labrusca L.) SUBMETIDAS À ADUBAÇÃO POTÁSSICA ${ }^{1}$
}

\author{
MARCO ANTÔNIO DALBÓ ${ }^{2}$, JEAN CARLOS BETTONI ${ }^{3}$, \\ JOÃO PETERSON PEREIRA GARDIN ${ }^{4}$, CLORI BASSO ${ }^{5}$
}

RESUMO - Videiras 'Isabel' enxertadas em porta-enxerto 'SO4' e 'IAC 766', e em pé-franco plantadas sobre Nitossolo foram tratadas anualmente com doses crescentes de $\mathrm{K}_{2} \mathrm{O}$, a $0 ; 60 ; 120$ e $180 \mathrm{~kg} \mathrm{ha}^{-1}$, durante 5 safras vitícolas (2007/2008; 2008/2009; 2009/2010;2010/2011;2011/2012). O delineamento experimental foi em faixas, com cinco repetições, sendo seis plantas por repetição, e os tratamentos, dispostos em esquema fatorial $4 \times 3$, com 12 tratamentos, correspondentes às quatro doses de adubação potássica e aos três portaenxertos. No estádio de mudança de cor da casca das bagas, coletaram-se pecíolos para determinar o teor de nutrientes no tecido foliar das uvas. Na ocasião da colheita, foram avaliados comportamentos vegetativos e produtivos, como produtividade, peso de poda, índice de Ravaz e características químicas da polpa das bagas, como sólidos solúveis totais, acidez total titulável e pH. O aumento da adubação potássica não representa ganho na produtividade na cv. Isabel nem no acúmulo de sólidos solúveis totais nas uvas. $\mathrm{K}$ e Mg nos pecíolos de uvas são influenciados pela forma de cultivo (enxertada ou pé-franco). Videiras 'Isabel' cultivadas em pé-franco têm menor capacidade de acúmulo de $\mathrm{K}$ e maior acúmulo de $\mathrm{Mg}$ nos pecíolos. Nas condições do solo em que foi desenvolvido o trabalho, não se justifica a adubação potássica do vinhedo.

Termos para indexação: Vitis, nutrição mineral, análise foliar.

\section{PRODUCTIVITY AND QUALITY OF GRAPES OF CV. ISABEL (Vitis labrusca L.) UNDER POTASSIUM FERTILIZATION}

\begin{abstract}
Grapevine 'Isabel' grafted on rootstock 'SO4' and 'IAC 766' and planted on ungrafted Nitosol were treated annually with increasing concentrations of $\mathrm{K}_{2} \mathrm{O}, 0 ; 60 ; 120$ and $180 \mathrm{~kg} \mathrm{ha}^{-1}$ for 5 wine-growing seasons $(2007 / 08,2008 / 09$, 2009/10 ,2010/11 and 2011/12). The experimental design was banded with five replications, with six plants per replication and the treatments in a $4 \times 3$ factorial design, with 12 treatments, corresponding to four doses of potassium fertilization and the three rootstocks. The stage of berries peel color change, stems were collected to determine the nutrient content in the grape leaves. At the time of harvest it was evaluated vegetative and productive behavior, such as productivity, weight pruning, Ravaz index, and analytical characteristics of berries, total soluble solids, titratable acidity and $\mathrm{pH}$ were evaluated. Increased potassium fertilization does not represent a gain in productivity in cv. Isabel nor the accumulation of soluble solids in grapes. $\mathrm{K}$ and $\mathrm{Mg}$ in petioles of grapes are influenced by the form of cultivation ( grafted or ungrafted ).'Isabel' vines grown on ungrafted have less capacity to accumulation of $\mathrm{K}$ and higher of $\mathrm{Mg}$ in the petioles. Under the conditions of the soil that was developed the research is not justified potassium fertilization of the vineyard .
\end{abstract}

Index terms: Vitis, nutrition, foliar analysis.

\footnotetext{
${ }_{1}^{1}$ (Trabalho 190-14). Recebido em: 06-06-2014. Aceito para publicação em: 09-04-2015.

${ }^{2}$ Eng. Agr., Ph.D., Epagri/Estação Experimental de Videira, C.P.21, CEP 89560-000, Videira-SC. E-mail: dalbo@epagri.sc.gov.br ${ }^{3}$ Eng. Agr., Especialista em Viticultura e Enologia, MSc., Doutorando em Produção Vegetal, UDESC - CAV, Avenida Luiz de Camões 2090, Bairro Conta Dinheiro, CEP 88520.000, Lages - SC. E-mail: jcbettoni@gmail.com

${ }^{4}$ Eng. Agr., Dr. Epagri/Estação Experimental de Videira, C.P.21, CEP 89560-000, Videira-SC. E-mail:joaogardin@epagri.sc.gob.br ${ }^{5}$ Eng. Agr., Dr. Epagri/Estação Experimental de Caçador, C.P.591, CEP 89500-000, Caçador-SC. E-mail:clori@epagri.sc.gob.br (aposentado)
} 


\section{INTRODUÇÃO}

A uva 'Isabel' (Vitis labrusca L.) é a principal cultivar produtora de uvas com origem americana presentes no Sul do Brasil, o que se deve a vários fatores, como alta produtividade, diversidade de uso (vinho, suco e mesa) e tolerância a doenças, como oídio e antracnose (RIZZON et al., 2000). Apesar de todos os esforços para substituir esta cultivar desde a década de 1930, a 'Isabel' representa cerca de 50\% da uva produzida no Rio Grande do Sul e em Santa Catarina (CAMARGO, 2003). Assim, seu cosumo se dá de diferentes formas, e o suco de uvas 'Isabel' é considerado a base do suco de uva brasileiro. Origina também um vinho típico, que em anos chuvosos é pouco colorido, sendo apreciado por uma faixa específica de consumidores.

Devido a sua rusticidade, como tolerância à filoxera, as plantas de uvas Isabel não necessitam de enxertia, não sendo uma prática obrigatória, podendo ser plantada em pé-franco, como ocorre principalmente nos vinhedos mais antigos. Vinhedos de pé-franco normalmente exigem um período de formação mais longo, mas atingem 80 a 100 anos com produções econômicas (CAMARGO, 2003).

$\mathrm{Na}$ região do Vale do Rio do Peixe-SC, têm-se observado alguns problemas nutricionais que parecem ser específicos da cultivar Isabel em pé-franco. São frequentes os casos de vinhedos com teores baixos de $\mathrm{K}$ nos pecíolos, mesmo com teores relativamente altos no solo. Nesses casos, os teores de Mg são normalmente elevados, ocorrendo notável diminuição da relação $\mathrm{K} / \mathrm{Mg}$ no tecido foliar. Esse problema foi inicialmente constatado num levantamento nutricional realizado na região (DALBÓ et al., 1989). Verificou-se que este desequilíbrio era observado principalmente em vinhedos da cultivar Isabel não enxertada (péfranco), o que levou à hipótese de que o problema teria origem genética. Dalbó et al. (2011) verificaram que o equilíbrio $\mathrm{K} / \mathrm{Mg}$ na cv. Isabel não foi alterado pelo nível de calagem, mas foi altamente influenciado pelo porta-enxerto utilizado. Embora existam variações entre porta-enxertos, a cv Isabel em péfranco tende a favorecer a absorção de $\mathrm{Mg}$ em relação a K, resultando em teores de $\mathrm{K}$ e a relação $\mathrm{K} / \mathrm{MG}$ nos pecíolos significativamente inferiores em relação ao uso dos porta-enxertos mais comuns.

A adubação da videira requer cuidados especiais, tendo em vista que esta espécie é sensível ao desequilíbrio nutricional entre $\mathrm{K}, \mathrm{Ca}$ e $\mathrm{Mg}$. O excesso de $\mathrm{K}$ favorece a elevação do $\mathrm{pH}$ do vinho, principalmente nos vinhos tintos; mas, em casos de deficiência, ocorre o inverso. A carência desse elemento interfere na síntese proteica, causando a elevação na quantidade de aminoácidos livres e retardando a maturação, e as plantas produzem cachos pequenos, duros, verdes e ácidos (MPELASOKA et al., 2003).

A absorção de nutrientes do solo é influenciada também por características genéticas das plantas. No caso da videira, é conhecida a influência do portaenxerto na absorção de nutrientes, especialmente com relação a K e Mg. Quando comparados a outros porta-enxertos, o SO4 e o 44-53M são conhecidos por acumularem teores mais altos de $\mathrm{K}$ em tecidos foliares (DELAS; POUGET, 1979; BRANCADORO et al., 1995). Essas variações na eficiência de absorção de nutrientes podem ser um fator de importância na nutrição das plantas e para estimar a necessidade de adubação (MIELE et al., 2009).

Tendo em vista que a cultivar Isabel em péfranco apresenta normalmente baixos teores de $\mathrm{K} \mathrm{e}$ altos teores de $\mathrm{Mg}$ nos pecíolos, faz-se necessário avaliar se o aumento da disponibilidade no solo aumenta o K nos pecíolos e se isto também se reflete na produtividade e na qualidade da uva. Caso este suposto desequilíbrio nutricional não se alterar com a adubação potássica, haveria necessidade de se desenvolver novos parâmetros para a interpretação da análise de pecíolos para a uva Isabel cultivada em pé-franco.

\section{MATERIAL E MÉTODOS}

O experimento foi realizado nas cinco safras vitícolas: 2007/2008, 2008/2009, 2009/2010, 2010/2011 e 2011/2012, em um pomar experimental de 8 anos, composto pela cv. Isabel, conduzido em latada, com espaçamento de $3,0 \times 1,5 \mathrm{~m}$, totalizando 2.222 plantas ha $^{-1}$, localizado no campo experimental da Epagri - Estação Experimental de Videira-SC. $\mathrm{O}$ delineamento experimental foi em faixas, com cinco repetições, sendo seis plantas por repetição, e os tratamentos, dispostos em esquema fatorial $4 \times 3$, com 12 tratamentos, que correspondem às doses de adubação potássica, 0; 60; 120 e $180 \mathrm{Kg} \mathrm{K}_{2} \mathrm{O} \mathrm{ha}^{-1} \mathrm{e}$ três porta-enxertos, sendo o $\mathrm{SO} 4$ (Vitis berlandieri $\mathrm{X}$ Vitis riparia), o IAC 766 (Ripária do Traviú X Vitis caribea) e o pé-franco da cv. Isabel.

Conforme a classificação de Köeppen (PANDOLFO et al., 2002), a área experimental está sob domínio climático $\mathrm{Cfb}$-Temperado (mesotérmico úmido e verão ameno) com temperaturas médias entre $16^{\circ} \mathrm{C}$ e $17^{\circ} \mathrm{C}$, e precipitação média anual de 1.300 a $1.500 \mathrm{~mm}$ e com altitude de $750 \mathrm{~m}$, e o solo é um Nitossolo Vermelho, segundo o Sistema Brasileiro de Classificação de Solos (EMBRAPA, 
2006).

Previamente, fez-se a análise de solo em cada parcela do experimento, na camada de 0 a $20 \mathrm{~cm}$ de profundidade, para a determinação dos valores de pH e dos teores de matéria orgânica, argila, P, K, Ca, $\mathrm{Mg}$, Al e $\mathrm{H}+\mathrm{Al}$ (Tabela 1). Verificada a necessidade de calagem e adubação de correção, fez-se correção em área total da parcela, interpretação conforme Comissão de Química e Fertilidade do Solo - RS/SC (2004). As aplicações de $\mathrm{K}_{2} \mathrm{O}$ foram realizadas uma vez por ano e, anualmente, no estádio de mudança de cor da casca, na área que corresponde à parcela. Os tratos culturais consistiram em aplicação de herbicida nas linhas de plantio e roçada mecânica nas entrelinhas.

Por ocasião da colheita, que se deu na primeira semana de março de cada safra vitícola, foi determinada a produtividade por planta $\left(\mathrm{kg} \mathrm{planta}^{-1}\right)$, calculada levando em conta a massa fresca dos cachos por planta. Para a avaliação das características químicas das uvas nas diferentes combinações portaenxerto/copa/adubação potássica, avaliaram-se o teor de sólidos solúveis, acidez titulável e $\mathrm{pH}$, sendo amostradas aleatoriamente 100 bagas por parcela (6 plantas), localizadas na zona apical, mediana e basal de diferentes cachos de ambos os lados da planta, conforme metodologia proposta por Rizzon e Mielle (2002). As análises de sólidos solúveis, acidez titulável e $\mathrm{pH}$ foram feitas de acordo com métodos descritos por Rizzon (2010).

Para determinar o vigor das plantas, utilizouse do índice de Ravaz, considerando a relação entre a produtividade e o peso do material podado de cada planta (medido na época da poda de frutificação).

Para determinar o teor de nutrientes no tecido foliar das uvas, coletaram-se, no momento da mudança de cor da casca, 50 pecíolos de folhas recém-maduras por parcela, analisando-se $\mathrm{N}, \mathrm{P}, \mathrm{K}$, $\mathrm{Ca}, \mathrm{Mg}$ e B, pela metodologia descrita por Tedesco et al. (1995).

Os dados foram submetidos à análise de variância, e as médias, comparadas pelo teste de Tukey, ao nível de 5\% de probabilidade, para os fatores qualitativos, e os níveis das doses de potássio, por meio de análise de regressão, utilizando-se do aplicativo R Development Core Team (2014).

\section{RESULTADOS E DISCUSSÃO}

As condições climáticas durante o período que compreenderam a execução do experimento são apresentados na Tabela 2. As temperaturas máximas e mínimas, bem como a precipitação pluvial foram consideradas normais para a região, quando comparadas com a média histórica dos últimos 20 anos.

Os resultados mostraram que não houve interação significativa entre o fator porta-enxerto e as doses de $\mathrm{K}_{2} \mathrm{O}$. Assim, considerou-se o efeito principal dos fatores.

Elevados teores de potássio foram encontrados no solo, anteriores à implantação do experimento (Tabela 1), e com o acréscimo anual das concentrações de $\mathrm{K}_{2} \mathrm{O}$, não se obteve incremento na produtividade, indicando que as quantidades de potássio existentes na fertilidade natural do solo são suficientes para a produção das videiras. Resultados semelhantes foram encontrados por Boonterm et al. (2010) ao trabalharem com a cv. Cabernet Sauvignon em solo com alta fertilidade de potássio, que não observaram efeito significativo da aplicação de fertilizante potássico nos componentes de rendimento. Essa situação é comum na região Sul do Brasil, onde se faz adubação potássica frequentemente de forma empírica, mesmo com alta fertilidade natural.

$\mathrm{Na}$ tabela 3, observa-se o efeito da forma de cultivo da uva cv. Isabel, enxertada ou em péfranco, com relação aos comportamentos vegetativo e produtivo, e as características químicas do mosto das bagas da uva Isabel na colheita. O efeito do portaenxerto na produtividade foi evidente, sendo que, ao enxertar cv. Isabel nos porta-enxertos SO4 e IAC 766, maiores são os rendimentos atingidos quando comparados com a Isabel cultivada em pé-franco. Ao estudar a influência de diferentes porta-enxertos para a cv. Niágara Rosada, Mota et al. (2009) observaram que, ao utilizar mudas de pé-franco, a produção foi 50 \% inferior em comparação ao uso de porta-enxerto, e da mesma forma ocorria redução no vigor das plantas, comprovado no momento da poda de inverno. Os resultados encontrados para a variável peso de poda corroboram essa afirmação. Constatou-se que, em plantas enxertadas, ocorre maior acúmulo de material podado, quando comparado com a cv. Isabel em péfranco, sendo que as videiras enxertadas no portaenxerto IAC 766 apresentaram maior quantidade de ramos no momento da poda, com $5,12 \mathrm{~kg}$ planta $^{-1}$, seguido pelo porta-enxerto SO4 com 4,32 $\mathrm{kg}_{\text {planta }}{ }^{-1}$ (Tabela 3).

Com relação ao índice de Ravaz, não foi 
verificado diferença significativa entre a forma de cultivo da cv. Isabel, enxertada ou em pé-franco (Tabela 3), indicando que as videiras apresentam níveis semelhantes de equilíbrio. Considerando que os valores foram superiores a 3,0, pode-se dizer que as plantas estão em um nível aceitável de balanceamento vegetativo e produtivo. Segundo Echenique et al. (2007), os valores para o índice de Ravaz entre 3 e 10 são considerados aceitáveis, enquanto Vasconcelos e Castagnoli (2000) frisam que um nível ótimo de equilíbrio se encontra entre 5 e 7.

Observou-se que o teor de sólidos solúveis foi influenciado pelos porta-enxertos (Tabela 3). Obtiveram maiores teores de sólidos solúveis no mosto da uva (17,6 ${ }^{\circ}$ Brix $)$, nas plantas de 'Isabel' enxertadas no porta-enxerto $\mathrm{SO}_{4}$, enquanto as plantas enxertadas em porta-enxerto IAC 766 e as cultivadas em pé-franco atingiram menores taxas de maturação, com 17,20 e $17,10^{\circ}$ Brix, respectivamente. Essa variação no teor de sólidos solúveis é comum ao analisar genótipos com diferentes características, sendo que porta-enxertos mais vigorosos tendem a prolongar o ciclo vegetativo, e em consequência a retardar o acúmulo de açúcares, e também pode ocorrer o inverso, porta-enxertos menos vigorosos com carga produtiva excessiva também podem retardar o acúmulo de açúcar, devido à condição de estresse (BRIGHENTI et al., 2011; WHITING, 2004).

Os menores valores de acidez total titulável (Tabela 3) foram obtidos quando a 'Isabel' foi enxertada sobre o porta-enxerto $\mathrm{SO} 4$, e não ocorreu diferença significativa entre cultivar a planta no portaenxerto IAC 766 e em pé-franco, as quais atingiram níveis mais elevados de acidez no mosto. As faixas de acidez encontradas neste estudo estão entre os valores encontrados por Rizzon et al. (2000), ao trabalharem com a cv. Isabel, no momento da colheita, que se deu no final de fevereiro,e encontraram níveis de acidez total entre 64 e $86 \mathrm{meq} \mathrm{L}^{-1}$.

A maioria dos trabalhos relatam o efeito positivo da aplicação de potássio no aumento da concentração de sólidos solúveis das bagas, como no estudo desenvolvido por El-Razek et al. (2011),no qual observaram que ao aplicar alta concentração de fertilizante potássico na videira 'Crimson Seedless', maiores eram os níveis de sólidos solúveis encontrados. Entretanto, neste estudo, não se obteve aumento no teor de sólidos solúveis com o aumento da concentração de $\mathrm{K}_{2} \mathrm{O}$, que se manteve em torno de $17,40^{\circ}$ Brix. O que pode justificar esses resultados é que já havia elevados teores de potássio no solo antes da implantação do experimento. Segundo Dalbó et al. (2011), os teores de potássio nos solos de vinhedos do
Alto Vale do Rio do Peixe são geralmente elevados. $\mathrm{O}$ efeito do aumento da dose de $\mathrm{K}_{2} \mathrm{O}$ foi observado na redução da acidez total do mosto das bagas (Figura 1). Submetendo estes valores à análise de regressão polinomial em função das doses de $\mathrm{K}_{2} \mathrm{O}$, observa-se que doses potássicas mais elevadas apresentaram menores teores de acidez no mosto de uvas 'Isabel', o que corrobora os estudos de El-Razek et al. (2011), ao aplicarem altas doses de potássio em vinhedos, observando diminuição da acidez no mosto das bagas.

Com relação ao $\mathrm{pH}$ do mosto das uvas (Figura 1), a análise de regressão revelou que, quando se aumenta a dose de $\mathrm{K}_{2} \mathrm{O}$ nos vinhedos, ocorre um aumento linear do $\mathrm{pH}$ do mosto das uvas 'Isabel', que mais tarde poderá ser um problema para a produção de um vinho de qualidade. Outro problema que ocorre naturalmente e é potencializado com a aplicação excessiva de potássio, é sua combinação com ácido tartárico, formando então bitartarato de potássio, que precipita durante o processo de vinificação e armazenamento, podendo reduzir excessivamente a acidez do vinho e afetar características visuais e sensoriais dos vinhos (DAVIES et al., 2006).

Os teores dos macronutrientes $\mathrm{N}$ e $\mathrm{K}$ encontrados nos pecíolos das plantas 'Isabel' enxertadas ou em pé-franco (Tabela 4) estão em um nível adequado,enquanto os níveis de $\mathrm{P}, \mathrm{Ca}$ e $\mathrm{Mg}$ estão em um nível acima do normal, este último em um nível altíssimo, reflexo da análise de solo (COMISSÃO DE QUÍMICA E FERTILIDADE DO SOLO - RS/SC, 2004).

O efeito do porta-enxerto no teor de nutrientes nos pecíolos foi evidente para o $\mathrm{K}$ e o Mg (Tabela 4), sendo que, em pé-franco, são menores as quantidades de $\mathrm{K}$ e maiores são os teores de $\mathrm{Mg}$ acumulado, em relação às plantas enxertadas. Já para os demais nutrientes, os porta-enxertos SO4 e IAC 766 obtiveram resultados semelhantes, não diferindo estatisticamente. Essa diferença no acúmulo de nutrientes $\mathrm{K}$ e $\mathrm{Mg}$ já foi observada por Dalbó et al. (2011) ao avaliarem a cv. 'Isabel' sobre os mesmos porta-enxertos ou em pé-franco, verificaram que esse maior acúmulo de $\mathrm{Mg}$ geralmente vem acompanhado de menor acúmulo de $\mathrm{K}$, resultando em baixa relação $\mathrm{K} / \mathrm{Mg}$.

Quando a cv. Isabel é enxertada, apresenta níveis adequados da relação dos macronutrientes $\mathrm{K} /$ $\mathrm{Mg}$, em torno de 3,44-3,68, nos porta-enxertos IAC 766 e SO4, respectivamente. De acordo com Delas e Pouget (1979), o intervalo adequado para a relação $\mathrm{K} / \mathrm{Mg}$ em pecíolos de uva coletados na mudança de cor da casca é entre 3 e 7. Valores abaixo de 1 indicam deficiência de $\mathrm{K}$, e acima de 10 , deficiência 
de Mg. Embora os valores abaixo de 1 tenham sido raros nos experimentos avaliados, valores inferiores a 3 foram bastante frequentes, sendo que, quando a 'Isabel' foi cultivada em pé-franco, menor foi a relação $\mathrm{K} / \mathrm{Mg}$, ficando abaixo de 3 , indicando que, quando cultivada em pé-franco, menor a capacidade de absorção pelas raízes dos macronutriente $\mathrm{K}$ e maiores os teores absorvidos de $\mathrm{Mg}$ (Tabela 4).
No Vale do Rio do Peixe, o cultivo de videiras 'Isabel' é uma fatia considerável da produção; dessa forma, devem-se considerar, no momento da adubação, todos os nutrientes, mas em especial o K e o $\mathrm{Mg}$, e se a planta está enxertada ou em pé-franco, definindo assim os níveis de fertilizantes a serem aplicados.

TABELA 1 - Resultado da análise de solo (média de todos os pontos) de vinhedo cultivado com a cv. Isabel Videira-SC, Brasil, 2014.

\begin{tabular}{|c|c|c|c|c|c|c|c|c|c|}
\hline Solo & ${ }^{1} \mathrm{pH}$ & M.O. & Argila & ${ }^{2} \mathrm{P}$ & ${ }^{2} \mathrm{~K}$ & $\mathrm{Al}$ & $\mathrm{Ca}$ & $\mathrm{Mg}$ & $\mathrm{H}+\mathrm{Al}$ \\
\hline & & \multicolumn{2}{|c|}{---------\%o--------- } & \multicolumn{2}{|c|}{----mg dm $\mathrm{dm}^{-3}----$} & ----- & $---c_{1}$ & $\mathrm{dm}^{-3}$ & - \\
\hline 1 & 5,8 & 4,3 & 79,5 & 7,0 & 172,2 & 0,0 & 11,1 & 4,8 & 5,0 \\
\hline
\end{tabular}

TABELA 2 - Condições climáticas durante o período experimental e em comparação com as médias dos últimos 20 anos Videira-SC, Brasil, 2014.

\begin{tabular}{|c|c|c|c|c|c|c|c|}
\hline \multicolumn{4}{|c|}{ Período experimental } & \multicolumn{4}{|c|}{ Média dos últimos 20 anos } \\
\hline \multirow{2}{*}{ Meses } & \multicolumn{3}{|c|}{ 2007/08 a 2011/12 } & \multirow{2}{*}{ Meses } & \multicolumn{3}{|c|}{$1993 / 94$ a 2012/13 } \\
\hline & $\mathrm{T}^{\circ}$ máx. $^{*}$ & $\mathrm{~T}^{\circ}$ mín.** & P.P.*** & & $\mathrm{T}^{\circ}$ máx.* $^{*}$ & $\mathrm{~T}^{\circ}$ mín.** & P.P.*** \\
\hline Setembro & 23,3 & 11,0 & 165,3 & Setembro & 22,9 & 10,8 & 182,3 \\
\hline Outubro & 24,6 & 13,5 & 223,5 & Outubro & 24,9 & 13,8 & 225,7 \\
\hline Novembro & 27,4 & 14,8 & 181,8 & Novembro & 27,2 & 14,7 & 163,1 \\
\hline Dezembro & 28,0 & 16,2 & 176,4 & Dezembro & 28,3 & 16,5 & 179,9 \\
\hline Janeiro & 28,3 & 17,1 & 197,3 & Janeiro & 28,6 & 17,7 & 203,2 \\
\hline Fevereiro & 29,1 & 17,8 & 174,4 & Fevereiro & 28,7 & 17,4 & 190,4 \\
\hline Março & 27,7 & 15,5 & 130,1 & Março & 28,0 & 15,9 & 138,1 \\
\hline média & 26,9 & 15,1 & 178,4 & média & 26,9 & 15,3 & 183,2 \\
\hline
\end{tabular}

TABELA 3 - Comportamento vegetativo e produtivo, e características analíticas das bagas da uva na colheita da cv. Isabel cultivada enxertada e em pé-franco Videira-SC, Brasil, 2014.

\begin{tabular}{lcccc}
\hline \multirow{2}{*}{ Variável } & \multicolumn{4}{c}{ Porta-enxerto } \\
\cline { 2 - 5 } & SO4 & IAC 766 & Isabel pé-franco & CV $(\%)$ \\
\hline Comportamento vegetativo e produtivo & & & & \\
\hline Produtividade $\left(\mathrm{kg} \mathrm{planta}^{-1}\right)$ & $14,02 \mathrm{a}$ & $15,46 \mathrm{a}$ & $3,15 \mathrm{~b}$ & 28,2 \\
Peso de poda $\left(\mathrm{kg} \mathrm{planta}^{-1}\right)$ & $4,32 \mathrm{~b}$ & $5,12 \mathrm{a}$ & $3,40 \mathrm{c}$ & 22,1 \\
Índice de Ravaz & $3,08 \mathrm{a}$ & $3,19 \mathrm{a}$ & $3,12 \mathrm{a}$ & 19,4 \\
\hline Características analíticas das bagas & & & & 6,3 \\
\hline Sólidos solúveis $\left({ }^{\circ}\right.$ Brix) & $17,46 \mathrm{a}$ & $17,20 \mathrm{~b}$ & $17,10 \mathrm{~b}$ & 12,8 \\
Acidez total titulável (meq L $\left.{ }^{-1}\right)$ & $61,54 \mathrm{~b}$ & $66,98 \mathrm{a}$ & $66,79 \mathrm{a}$ & 2,4 \\
pH & $3,50 \mathrm{~ns}$ & 3,50 & 3,49 & \\
\hline
\end{tabular}

Médias seguidas da mesma letra minúscula na linha não diferem estatisticamente, pelo teste de Tukey ( $\mathrm{p} \leq 0,05)$. *ns- não significativo **Os valores expressos na tabela referem-se à média das 5 safras vitícolas; *** As concentrações de $\mathrm{K}_{2} 0$ aplicadas não apresentaram interação com a forma de cultivo (enxertada ou em pé-franco), dessa forma os dados não estão expressos na tabela. 
TABELA 4 - Teor de macronutrientes e relação $\mathrm{K} / \mathrm{Mg}$, em $\mathrm{g} \mathrm{kg}^{-1}$, em pecíolos de folhas de uva coletadas na mudança de cor da casca, na cv. Isabel cultivada enxertada e em pé-franco Videira-SC, Brasil, 2014.

\begin{tabular}{ccccr}
\hline \multirow{2}{*}{ Teor de nutrientes nos pecíolos } & \multicolumn{5}{c}{ Porta-enxerto } \\
\cline { 2 - 5 } & SO4 & IAC 766 & Isabel pé-franco & CV (\%) \\
\hline $\mathrm{N}$ & $8,03 \mathrm{~ns}$ & 7,96 & 7,99 & 8,5 \\
$\mathrm{P}$ & $3,68 \mathrm{~ns}$ & 3,60 & 3,58 & 12,4 \\
$\mathrm{~K}$ & $22,37 \mathrm{a}$ & $22,63 \mathrm{a}$ & $16,80 \mathrm{~b}$ & 22,3 \\
$\mathrm{Ca}$ & $21,02 \mathrm{~ns}$ & 21,44 & 20,57 & 23,5 \\
$\mathrm{Mg}$ & $7,47 \mathrm{~b}$ & $7,60 \mathrm{~b}$ & $8,64 \mathrm{a}$ & 11,3 \\
$\mathrm{~K} / \mathrm{Mg}$ & $3,68 \mathrm{a}$ & $3,44 \mathrm{a}$ & $2,22 \mathrm{~b}$ & 12,1 \\
\hline
\end{tabular}

Médias seguidas da mesma letra minúscula na linha não diferem estatisticamente, pelo teste de Tukey (p $\leq 0,05)$. *ns- não significativo; ** Os valores expressos na tabela referem-se à média das 5 safras vitícolas; *** As concentrações de $\mathrm{K}_{2} 0$ aplicadas não apresentaram acréscimo no teor de nutrientes nos pecíolos, dessa forma os dados não estão expressos na tabela.
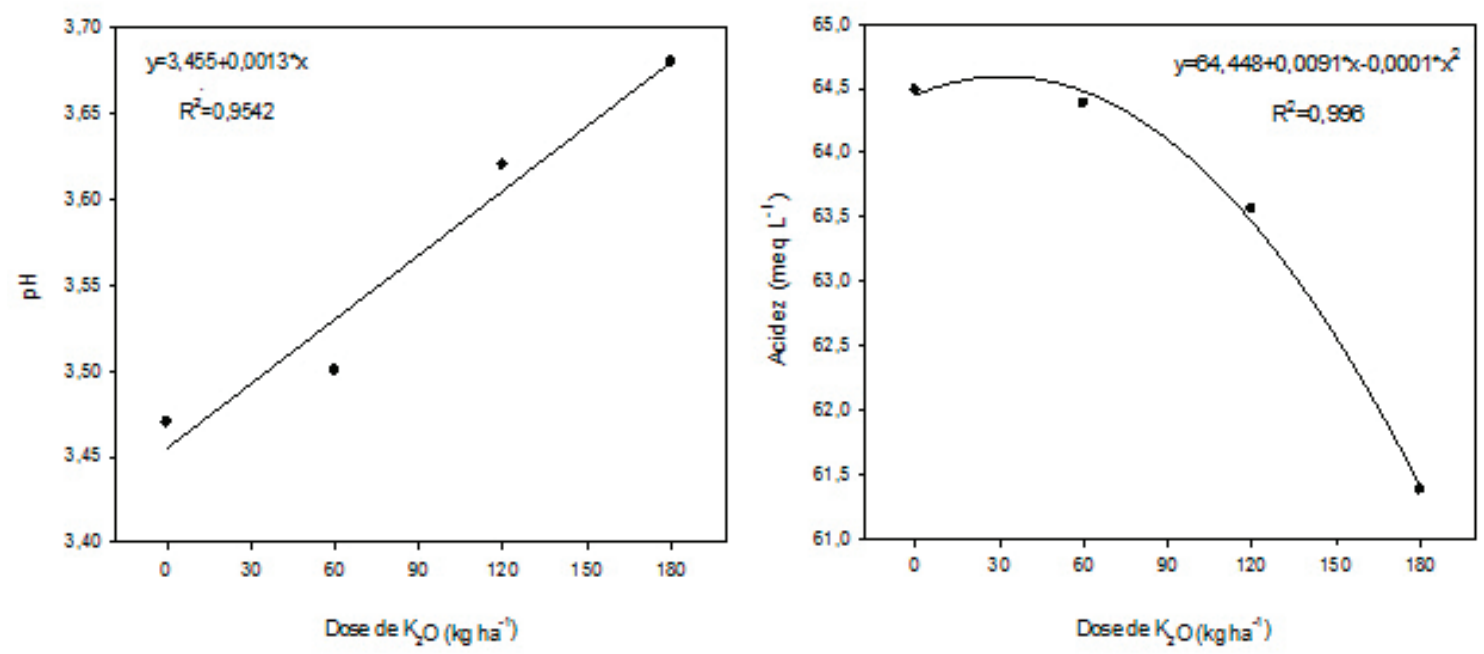

FIGURA 1 - Efeito da aplicação de doses crescentes de $\mathrm{K}_{2} \mathrm{O}$ no pH e na acidez total do mosto de uvas da cv. Isabel, em Videira-SC, Brasil. 


\section{CONCLUSÕES}

-O aumento da adubação potássica não representa ganho na produtividade na cv. Isabel nem no acúmulo de sólidos solúveis totais nas uvas, em solos com alto teor de potássio.

-K e Mg nos pecíolos de uvas são influenciados pela forma de cultivo (enxertada ou em pé-franco).

-Videiras 'Isabel' cultivadas em pé-franco apresentam baixa capacidade de acúmulo de $\mathrm{K}$ e alto acúmulo de $\mathrm{Mg}$ nos pecíolos, o que resulta em baixa relação $\mathrm{K} / \mathrm{Mg}$.

- Elevadas concentrações de $\mathrm{K}_{2} 0$ diminuem a acidez e aumentam o $\mathrm{pH}$ do mosto.

- Nas condições do solo em que foi desenvolvido o trabalho, não se justifica a adubação potássica do vinhedo.

\section{REFERÊNCIAS}

BOONTERM, V.; SILAPAPUN, A.; BOONKERD, N. Effects of nitrogen, potassium fertilizers and clusters per vine on yield and anthocyanin content in Cabernet Sauvignon grape. Suranaree Journal of Science and Technology, Nakhon Ratchasima,v. 17, n. 2, p. $155-163,2010$.

BRANCADORO, L.; VALENTI, L.; REINA, A. Rootstock effect on potassium content of grapevine. Acta Horticulture, The Hague, n. 383, p. 115-124, 1995.

BRIGHENTI, A.F.; RUFATO, L.; KRETZSCHMAR, A.A.; SCHLEMPER, C. Desempenho vitivinícola da Cabernet Sauvignon sobre diferentes porta-enxertos em região de altitude em Santa Catarina. Revista Brasileira de Fruticultura, Jaboticabal, v. 33, n. 1, p.96-102, 2011.

CAMARGO, U. A. Uvas americanas e híbridas para processamento em clima temperado. Bento Gonçalves: Embrapa Uva e Vinho, 2003. Disponível em: http://www.cnpuv.embrapa.br/publica/sprod/ UvaAmericanaHibridaClimaTemperado/cultivar. htm. Acesso em: 2 fev. 2014.

COMISSÃO DE QUÍMICA E FERTILIDADE DO SOLO. Manual de adubação e calagem para os estados do Rio Grande do Sul e Santa Catarina. 10.ed. Porto Alegre: SBCS - Núcleo Regional Sul/ UFRGS, 2004. 400p.
DALBÓ, M. A.; BECKER, M.; BASSO, C.; STUKER, H. Levantamento do estado nutricional da videira em Santa Catarina por análise de solo e tecido. Revista Brasileira de Ciência do Solo, Viçosa, MG, v. 13, n.3, p. 335-340, 1989.

DALBÓ, M. A.; SCHUCK, E.; BASSO, C. Influence of rootstock on nutrient content in grape petioles. Revista Brasileira de Fruticultura, Jaboticabal, v. 33, p. 941-947, 2011.

DAVIES, C.; SHIN, R.; LIU, W.; THOMAS, M.R.; SCHACHTMAN, D.P. Transporters expressed during grape berry (Vitis vinifera L.) development are associated with an increase in berry size and berry potassium accumulation. Journal of Experimental Botany, Lancaster, v. 57, n. 12, p. 3209-3216, 2006.

DELAS, J.; POUGET, R. Influence du greffage sur la nutrition minerale de la vigne. Consequences sur la fertilization. Connaissance de la vigne et du vin, Bordeaux, v.13, n.4, p. 241-261, 1979.

ECHENIQUE, M.C.; APCARIAN, A.; REEB, P.; ARUANI, M.C. Growth-yield relationship of grapevine cultivars on soils with hardened layers, Alto Valle of the Rio Negro, southern wine-growing region of Argentina. Agricultura Técnica, Chile, v. 67 , n. 3, p. 262-270, 2007.)

EMBRAPA - Empresa Brasileira de Pesquisa Agropecuária. Sistema brasileiro de classificação de solos. 2.ed. Rio de Janeiro: Embrapa Solos, 2006. $306 \mathrm{p}$.

EL-RAZEK, A.; TREUTTER, D.; SALEH, M.M.S.; EL-SHAMMAA, M.; FOUAD, A. A.; ABDELHAMID, N. Effect the nitrogen and potassium fertilization on productivity and fruit quality of 'Crimson Seedless' grape. Agriculture and Biology Journal of North America, Milford, v. 2, n. 2, p. 330-340, 2011.

MIELE, A.; RIZZON, L.A.; GIOVANNINI, E. Efeito do porta-enxerto no teor de nutrientes em tecidos da videira 'Cabernet Sauvignon'. Revista Brasileira de Fruticultura, Jaboticabal, v. 31, n. 4, p. 11411149, 2009. 
MOTA, R.V.; SOUZA, C.R.; FAVERO, A.C.; SILVA, C. P. C.; CARMO, E. L.; FONSECA, A. R.; REGINA, M. A. Produtividade e composição físicoquímica de bagas de cultivares de uva em distintos porta-enxertos. Pesquisa Agropecuária Brasileira, Brasília, v. 44, n. 6, p. 576-582, 2009.

MPELASOKA, B.S; SCHACHTMAM, D.P.; TREEBY, M.T.; THOMAS, M.R. A review of potassium nutrition in grapevines with special emphasis on berry accumulation. Australian Journal of Grape and Wine Research, Glen Osmond, v. 9, p. 154-158, 2003.

PANDOLFO, C. et al. Atlas climatic digital do Estado de Santa Catarina. Florianópolis: Epari, 2002. CD-ROM.

R DEVELOPMMENT CORE TEAM. R: A language and environment for statistical computing. Vienna: R Foundation for Statistical Computing, 2014. Disponível em: $<$ http://www.R-project.org/>. Acesso em: 20 jan. 2014.
RIZZON, L.A; MIELE, A; MENEGUZZO, J. Avaliação da cv. Isabel para a elaboraçãode vinho tinto. Ciência e Tecnologia de Alimentos, Campinas, v.20, n.1, p.115-121, 2000.

RIZZON, L.A. Metodologia para análise de mosto e suco de uva. Brasília: Embrapa Informação Tecnológica, 2010. 78p.

RIZZON, L.A; MIELE, A. Avaliação do cv. Cabernet Sauvignon para elaboração de vinho tinto. Ciência e Tecnologia de Alimentos, Campinas, v.22, n. 2, p. 192-198, 2002.

TEDESCO, M.J; GIANELLO, C.; BISSANI, C.A.; BOHNEN, H.; VOLKWEISS, S.J. Análises de Solos, plantas e outros materiais. 2.ed. Porto Alegre: Universidade Federal do Rio Grande do Sul, 1995. 215p. (Boletim Técnico, 5)

WHITING, J.R. Grapevine rootstocks. In: DRY, P.R.; COOMBE, B. G. (Ed.). Viticulture: resources in Austrália. Ashford: Winetitles, 2004. p. 167-188.

VASCONCELOS, M.C.; CASTAGNOLI, S. Leaf canopy structure and vine performance. American Journal of Enology and Viticulture, Davis, v. 51, n. 4 , p. 390-396, 2000. 